\title{
O Design Sistêmico como método de inovação aplicado a fornos tradicionais de cerâmica vermelha no Amazonas - Brasil
}

\author{
Cordeiro-Mota, Sheila ${ }^{a}$; Pacheco, Karla Mazarelo ${ }^{b}$ \& Hernandis-Ortuño, Bernabé ${ }^{c}$ \\ ${ }^{a} \mathrm{PhD}$, candidate at Universitat Politècnica de València, Spain. sheimota@yahoo.com.br. \\ ${ }^{b} \mathrm{PhD}$, Professor at Universidade Federal do Amazonas, Brazil. karlamazarelo@hotmail.com. \\ ${ }^{\mathrm{c}} \mathrm{PhD}$, Full Professor, Universitat Politècnica de València, Spain. bhernand@degi.upv.es.
}

\section{Resumo}

Este trabalho analisa alguns sistemas tradicionais de cocção cerâmica, propondo uma nova configuração sistêmica. Mediante a avaliação da produção de blocos cerâmicos, tomamos como foco de pesquisa o processo de queima em fornos tradicionais, levando em consideraçao questões econômicas e sociais do Amazonia brasileira. Esta pesquisa tem como propósito, desenvolver um novo sistema, considerado eco-eficiente e sustentável, unindo o que é tecnicamente viável na área de tecnologias limpas, com o que é culturalmente desejável em relação aos produtos sem prejudicar os usuários de seus sistemas, bem como as relações sociais de produção que estão envolvidas durante o processo. Com base em dados levantados a partir de visitas técnicas realizadas as empresas de cerâmica da região do Iranduba e entrevistas a expertises do setor a nivel nacional, observou-se outros aspectos que prejudicam a qualidade do processo de cocção cerâmica. Geralmente se utilizam fornos com queima ineficiente da lenha ou outros insumos energéticos, resultando em uma série de inconvenientes que comprometem o desempenho produtivo e econômico, causando danos ambientais, sobretudo quando se trata das pequenas e médias empresas. Em se tratando de uma análise sobre o estudo de caso, a interpretação dos dados coletados se caracteriza por um esquema não rígido, considerando que os elementos envolvidos compõem blocos conceituais que visam gerar os requisitos e parâmetros considerados essenciais a projetação de um novo sistema de queima cerâmica. Buscando materializar as necessidades e objetivos do projeto, se lançou mão do modelo de Design concorrente, abordando os aspectos formais, ergonômicos e funcionais do sistema, incorporando a estes o contexto social, econômico, tecnológico e ambiental.

Keywords: Design, estudo sistêmico, fornos olaria.

\begin{abstract}
This work analyses some traditional brick kilns cooking systems, and proposes a new systemic configuration. Upon evaluation of the production of ceramic blocks, we took the burning process in traditional ovens as the research focus, taking into account economic
\end{abstract}


and social issues of the Brazilian Amazon. This research aims to develop a new system, that can be consireded both eco-efficient and sustainable. By putting together what is technically feasible in the area of clean technologies, what is culturally desirable for products without harming the users of their systems, we respect the social relations of production involved in the process. Based on data collected from technical visits in the ceramic companies of the Iranduba region, as well as the results of interviews with the expertise of the national industry, we detected other aspects affecting the quality of the ceramic firing process. In general, the stoves use inefficient burning of wood and other energy inputs, yielding a number of drawbacks that compromise the productive and economic performance, causing environmental damage, particularly when it occurs in small and medium enterprises. In this case study, the interpretation of the collected data is characterized by a non-rigid scheme, considering that the involved elements make conceptual blocks aimed at generating the requirements and parameters considered essential to design a new ceramic firing system. To realize the needs and objectives of the project, we made use of the concurrent model design, by addressing the formal, ergonomic and functional system aspects, and incorporating the social, economic, technological and environmental contexts.

Keywords: Design, systemic study, bricks kilns.

\section{Introdução}

Segundo dados da NEAPL/AM, 2009, a maioria das empresas de cerâmica vermelha do Amazonas, se configuram como micro e pequenas empresas à margem dos avanços da modernização tecnológica e/ou administrativa. Em sua maioria, as empresas estão organizadas com estrutura familiar, onde tanto os proprietários quanto os empregados exercem funções diversificadas.

Os aglomerados produtivos que juntos poderão evoluir para a formação de um único Arranjo Produtivo Local - APL, são compostos pelos Polos cerâmicos do Ariaú, Cacau-Pirêra e Iranduba, onde se encontram instaladas 27 empresas cerâmicas, das quais mais da metade está instalada no Polo de Cacau-Pirêra, na margem direita do rio Negro, frontal à sede municipal de Manaus (SEPLAN, 2009).

O setor da cerâmica vermelha emprega como combustíveis, principalmente a lenha nativa (50\%) e resíduos de madeira (40\%): cavaco, serragem, briquetes e outros resíduos. Dados do setor apontam uma tendência no aumento do uso de lenha de reflorestamento visando à sustentabilidade energética do empreendimento e levando a um excedente de biomassa para comercialização de madeira, contudo essa é uma tendência que não se aplica ainda ao âmbito de estudo desta pesquisa, havendo ainda necessidade de intervenções por parte do setor público, no que tange ao desenvolvimento de programas de reflorestamento no Amazonas voltado para esse segmento da indústria ou demais segmentos (SEPLAN - AM, 2009).

O bloco cerâmico também é conhecido como tijolo de oito furos, sendo este o produto cerâmico mais consumido em Manaus, onde $90 \%$ destes blocos provêm da região de Manacapuru e Iranduba. Esta produção abastece quase totalmente a capital, cuja distribuição da produção se divide do seguinte modo: $25 \%$ são de olarias de grande porte com capacidade de produção que pode chegar a 50.000 tijolos por dia; $25 \%$ são de olarias de médio porte com capacidade média de 30.000 tijolos diários; e os $25 \%$ restantes são de olarias de pequeno porte que não passam de 10.000 tijolos por dia. Porém, esse material é um dos que ocasiona um elevado índice de perda na construção civil, chegando a um valor médio de 13\% (FURG, 2005). 
Em relação ao custo médio da indústria cerâmica da região, o consumo da lenha e derivados se destaca dos demais, indicando baixa eficiência dos fornos e alto custo desse insumo. Também se observa os custos com energia elétrica, contudo os custos administrativos e referentes a comercialização são baixos. Essa relação ocorre em razão da pequena estrutura administrativa e ausência de estrutura comercial na maioria das empresas (NEAPL/AM, 2009).

Dentre as principais questões que afetam o Setor Cerâmico, principalmente o Segmento de Cerâmica Vermelha, destaca-se a baixa qualidade dos produtos, observada em uma parcela significativa da produção, em função das grandes variações dimensionais e baixa resistência mecânica observada. Este fato gera grandes perdas durante o processo produtivo. (SILVA 2007). Dentre outros fatores que influenciam essa baixa qualidade dos blocos cerâmicos, há a natureza do material utilizado, sendo a fase da queima o processo mais crítico conforme observado durante as visitas técnicas realizadas às empresas da região.

Este artigo apresenta um recorte da pesquisa, destacando uma avaliação, por parte de especialistas do setor da indústria de ceramica vermelha, sobre os processos tradicionais da produção de cerâmica vermelha, especificamente sobre os sistemas de queima ainda utilizados pelas pequenas e médias olarias a nível de Brasil. , considerando como ambiente de estudo o Pólo oleiro de Iranduba e Manacapuru, cidades próximas a Manaus, capital do Estado do Amazonas - Brasil.

Esta pesquisa se delimita aos aspectos tecnológicos sobre o processo de produção de blocos cerâmicos em fornos tradicionais que fazem uso de insumos madereiros e que apresentam as respostas a partir de um estudo sistêmico, com base no Modelo de Design Concorrente (Hernandis 2003). O estudo realizado propõe uma adaptação tecnológica entre os sistemas de queima, que funcionam a partir do modo de queima com a chama em sentido desecendente e o sistema de queima conhecido como downdraft, de acordo com os trabalhos de Khan et al (1989) apud Borges (1994), citado por Mota et al (2015), os quais demonstraram que a combustão por processo downdraft propicia a queima da lenha praticamente completa, diferenciando-se entre os processos de queima tradicionais. Esta ocorre por meio de modificações morfológicas e geométricas na câmara de combustão, tornando a combustão adiabática e invertendo o fluxo de ar.

\section{Abordagem Metodológica}

Em razão da concepção de um novo sistema de queima para cerâmica estrutural, considerando os aspectos relativos ao método de pesquisa utilizado, lançou-se mão de uma abordagem metodológica híbrida, incorporando a esta elementos descritivos de base teórica, observacional e de cunho qualitativo por meio de pesquisa junto a expertises e empresários do setor da cerâmica vermelha a nível nacional e local.

Esta pesquisa analisa dois sistemas tradicionais de cocção cerâmica, propondo uma geometrização sistêmica analítica com base no método sugerido por Hernandis (2003), cujo propósito se fundamenta sob as práticas orientadas para analisar e desenvolver com mais especificidade os aspectos funcionais, formais, ergonômicos, culturais, sociais e tecnológicos do produto. Os resultados preliminares desta aplicação gerou um novo modelo respeitando os parâmetros conceituais do sistema em estudo.

O modelo de design concorrente, baseado na teoria geral de sistemas, proposto por Hernandis (2003) para a criação de produtos inovadores, representado pela figura 01, centra-se na definição de todos componentes intervenientes no processo de design, para definir o produto. Com base em toda a informação recopilada, definem-se os aspectos formais, funcionais e ergonômicas do produto como subsistemas principais na formulação de atributos e na emissão de variáveis que circulam dentro de um sistema vivo para a formulação de uma solução (Paixão-Barradas, Pacheco, \& Hernandis, 2012) apud (Mota et al 2015) e (Rivera et al 2015). O uso de um modelo sistémico especifico, como este, justifica-se pela possibilidade que este oferece em poder examinar as variáveis necessárias para o design do produto, considerando a dinamicidade e constante atualização que os produtos devem possuir para manter-se no mercado ou cativar outros mercados. Uma forte característica deste modelo é sua plasticidade através da retroalimentação das informações e consequentemente do feedback de todas as partes que compõem o modelo, nas quais as próprias variáveis se tornam nas responsáveis por analisar, comprovar e manter todo 
o sistema ativo e controlado (Pacheco, Hernandis, \& Paixão-Barradas, 2012). Tomando como referência as definições de Briede e Hernandis (2011), as análises dos subsistemas e relações comuns entre os dois tipos de fornos estudados, demonstram como a partir da definição abstrata, inicial do projeto, elementos comuns podem ser definidos para uma representação maior de produtos, independentemente de suas características de forma. (BRIEDE e HERNANDIS, 2011).

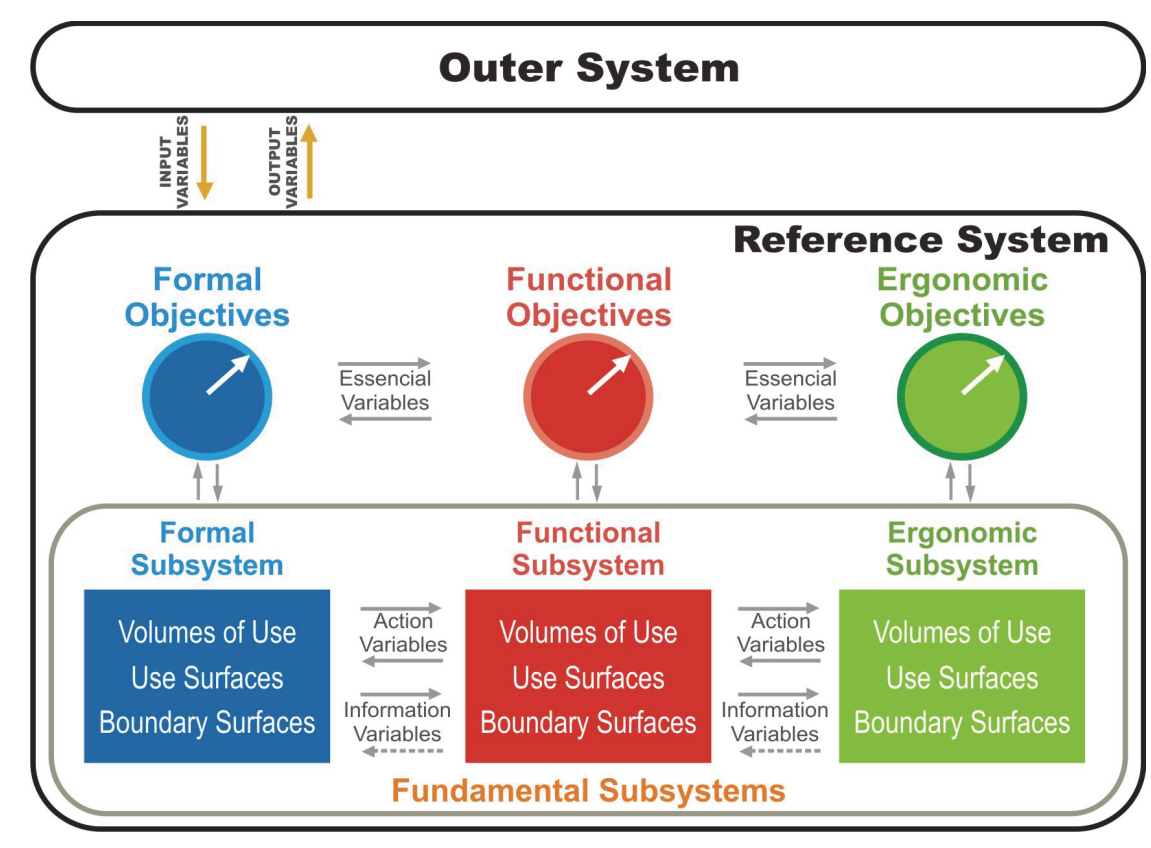

Fig. 1 Modelo de Design Concurrente. Fonte: Adaptado de Hernandis (2003) e Rivera et al (2015).

Esta fase da pesquisa, corresponde aos aspectos práticos, especificamente as fases de coleta e compilação de dados em busca de informações junto a especialistas, bem como no desenvolvimento de uma aplicação, seguindo os conceitos estabelecidos pelo modelo de design concorrente. Desta forma se evidencia descritivamente as variáveis essenciais e informacionais do sistema em estudo, para propor um novo conceito que atenda os objetivos da pesquisa.

Ficou estabelecido, por meio do percurso metodológico atribuído a esta pesquisa, que as variáveis que alimentam e movimentam este sistema teria como fonte os resultados das pesquisas teóricas, por meio de consulta bibliográfica, pesqusia de campo e entrevistas a expertises do setor da indústria e da pesquisa, assim como empresários do pólo oleiro estudado. Os objetivos que direcionam a pesquisa prática no que se refere a entrevista a especialistas, busca analizar por meio de uma estrutura de questionários virtuais, basicamente três objetivos principais, estando presentes em todos os contetxtos, quais sejam: a) avaliar o que existe; b) levantar as necesidades para resolução do problema e; c) validar as quetões conceituais desenvolvidas para o sistema em estudo.

Antes de elaborar o instrumento da entrevista, buscou-se entender os fundamentos psico-sociais que envolve o processo de entrevistas. O desenvolvimento do instrumento de pesquisa a especialistas obedece a uma estrutura lógica, conforme sugerido por Dillman (1978, p. 12), que afirma: ... "o processo de mandar um questionário a respondentes em potencial, conseguir que completem e devolvam o questionário de maneira honesta pode ser visto como caso especial de 'troca social' ". Complementando a abordagem, o mesmo autor também coloca que há três fatores que devem ser considerados a fim de maximizar a qualidade das repostas (Dillman, 1978, p. 18), como por exemplo: reduzir o custo de resposta por parte do respondente, recompensar o respondente e establecer confianaça. 
O questionário elaborado considera o objetivo da entrevista em termos dos conceitos a serem pesquisados e da população-alvo. Utilizando-se como ponto de partida as considerações de Schuman \& Kalton (1985), resumidas na Figura 02. Diante do esquema que esclarece a relação existente entre os elementos que constituem uma entrevista, apresenta-se na seqüencia seus objetivos, os conceitos derivados destes, bem como a identificação da população e da amostra. Também se apresentam os elementos técnicos da entrevista, como: a) Os itens da entrevista, representados pelas questões / perguntas do instrumento, constantes anexados ao relatório final desta pesquisa; b) $\mathrm{O}$ modo de administrar, representado pelo meio de difusão da entrevista (questionário online); c) Método de edição e codificação dos dados; d) Método de processamento dos dados e; e) Análise dos dados por meio de representação gráfica.

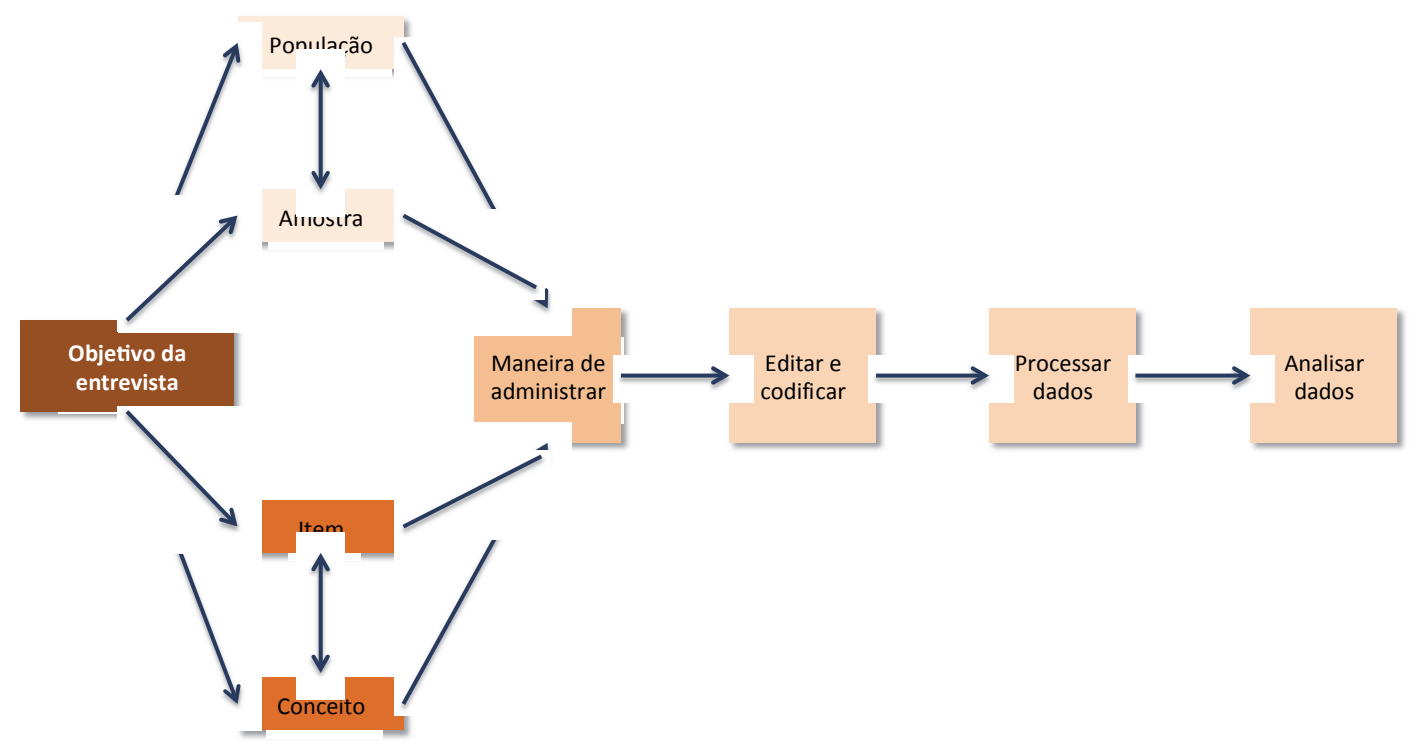

Figura 02: Arquitetura conceitual de uma entrevista. Fonte: Schuman \& Kalton (1985)

O objetivo principal desta entrevista foi coletar dados que consolidassem as informações sobre a temática desenvolvida na pesquisa. Os itens da entrevista envolvem os aspectos relacionados ao processo produtivo com ênfase na queima em fornos tradicionais. Desta forma foram analisados os aspectos tecnológicos, ergonômicos, ambientais e culturais, compondo parte do contexto investigativo para o desenvolvimento de um modelo de forno mais eco eficiente, que responda sobretudo as necessidades de desenvolvimento sustentável para este setor.

O universo estudado, seleção e tamanho da amostra investiga um grupo de especialistas e empresários locais, que pelo critério de tipicidade faz parte do contexto investigado. Foram selecionados 18 expertises das áreas de tecnologia cerâmica, ciências ambientais, ergonomia industrial, materiais industriais, engenharia civil e engenharia de produção, assim como 8 empresários de pequeno e médio porte do Polo Oleiro de Iranduba. O tipo de amostra dentro do espaço amostral definido se caracteriza como não-pro balística, ou seja, selecionada pelos critérios de acessibilidade e tipicidade.

O processo de análise e interpretação dos dados desta pesquisa varia em função dos diferentes aspectos que estruturam a mesma, e seguem os passos orientados por Carvalho e Vergara, 2002, p. 84.

\section{Discussão dos resultados da entrevista a expertises e empresários do setor da cerâmica industrial.}

O método de pesquisa qualitativa utilizada se caracterizou como: a) Estudo de Caso: Este método de pesquisa qualitativa é um estudo profundo de um indivíduo ou fenômeno específico no seu contexto de vida; b) A Coleta de dados: Entrevistas - Questionários escritos e estudos indutivos sobre aspectos, 
percepções e pensamentos observados a partir dos estudos em pesquisa exploratória e; c) Organização da entrevista. em 4 (quatro) blocos conceituais, abordando os aspectos relacionados a pesquisa, cujos gráficos encontram-se anexado ao relatório de pesquisa geral e que por uma questão didática não se insere aqui neste artigo.

As primeiras questões apresentadas aos especialistas, conforme mostra o gráfico 01, detectou o nível de aceitação dos sistemas tradicionais de cocção cerâmica, que ainda fazem uso de combustíveis lenhosos. Os resultados da entrevista apontam que estes sistemas ainda são indispensáveis para o abastecimento da cadeia produtiva, considerando que grande parte dos produtores de tijolos e telhas, dentro do âmbito nacional, ainda fazem uso destes sistemas por questões de viabilidade técnica e sobretudo econômica.

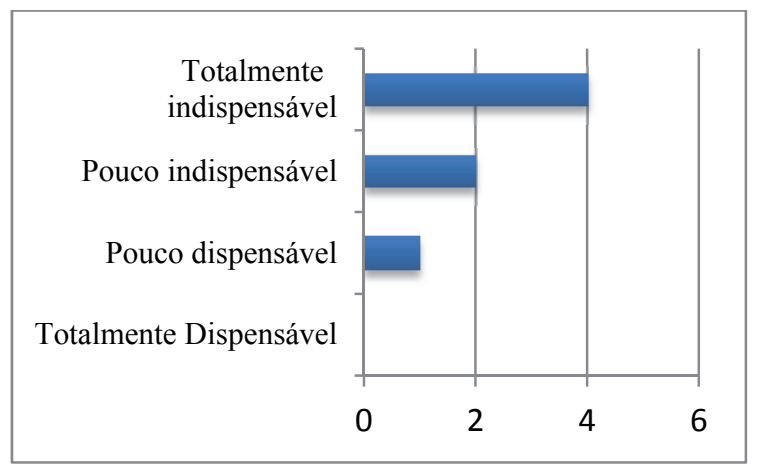

Gráfico 01: o nivel de aceitação dos sistemas tradicionais de cocção cerâmica

Conforme apresenta o gráfico 02, os expertises corroboram com os dados apontados pela literatura consultada (VASCONCELOS et al 2012), estes fornos ainda predominam o segmento da indústria cerâmica nacional. Desta forma pode se dizer que o desenvolvimento de um sistema de queima ecoeficiente irá contribuir de forma significativa para o setor a nível nacional. Isso fortalece a ideia desenvolvida por esta pesquisa, que é tornar mais eco eficiente o sistema tradicional da queima cerâmica.

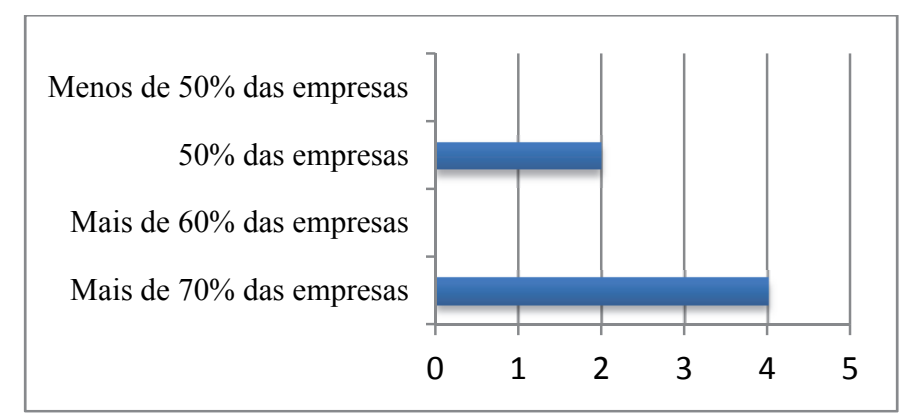

Gráfico 02: Predominancia dos fornos de queima tradicional no cenário nacional.

Considerando a hegemonia da área de conhecimentos dos expertos entrevistados, são agrupados por blocos os aspectos tecnológicos, ergonômicos, ambientais e sócio/culturais. O bloco de entrevista referente aos aspectos sócio culturais foram dirigidos diretamente aos empresários da zona estudada (polo oleiro de Iranduba). Os aspectos investigados junto aos expertises e empresearios do setor forneceram os dados necessários para consolidar as ideias pré-estabelecidas por meio de levantamento bibliográfico e observacional em campo, além disso, estes dados alimentaram o modelo de design concorrente, utilizado como método de desenvolvimento do novo sistema e foram explorados em quatro blocos distintos por 
meio da entrevista. Estes blocos perfazem todo os contexto investigado e extrapolado pelo MDC, sendo estes:

1) $\mathrm{O}$ aspecto tecnológico buscou identificar características gerais da produção com foco na queima envolvendo o sistema exterior, de acordo com o M.D.C (Hernadis 2003), considerando a tipologia dos fornos tradicionais mais utilizados por pequenas e medias empresas. Os expertises do setor da indústria foram questionados quanto as características das necessidades de inovação em função da acessibilidade tecnológica e sobre os critérios de produtividade, ganhos econômicos e qualitativos da produção, além das características estruturais e operacionais mais comuns e mais representativas, entre os modelos de fornos "abóboda" e "paulistinha", que de acordo com Vasconcelos et al (2012), estes modelos de fornos fazem parte do contexto produtivo de quase todas as empresas do polo oleiro do Estado do Amazonas.

2) O aspecto ergonômico: Qualquer ambiente de trabalho deve buscar adequações ergonômicas que reduzam as exigências biomecânicas e cognitivas dos operadores do sistema, permitindo que o mesmo se sinta confortável para executar suas tarefas. Os atributos macro ergonômicos da produção, foram identificados por meio de algumas características, com foco na queima, envolvendo os aspectos do ambiente de trabalho e sua influência sobre o operador do sistema de queima. Além disso, foram detectados alguns aspectos que relacionam a tipologia dos fornos tradicionais utilizados, como disfunções e riscos acidentais sofridos pelo executor da tarefa destes sistemas.

Considerando o contexto macro ergonômico, os entrevistados avaliaram por grau de importância as seguintes questões: a) o grau de importância da exposição ao calor proveniente do processo de queima sofrido pelo operador do sistema; b) o grau de importância dos riscos acidentais, aos quais está exposto o operador do sistema; c) o grau de importância da pouca iluminação durante a execução da tarefa do forneiro; d) o grau de importância do ruído para com o desempenho do operador do forno; e) o grau de importância dos agentes químicos, resultantes das características ambientais locais, as quais estão expostos os operadores do sistema de queima e; f) o grau de importância da umidade resultante das características ambientais locais, as quais estão expostos os operadores do sistema de queima;

3) Aspecto Ambiental: Este bloco aborda os aspectos tecnológicos da produção dos fornos que fazem uso de combustíveis madeireiros, considerando os parâmetros ideais de otimização da produção em termos de ganhos produtivos e ambientais, avaliando por grau de importância as seguintes questões: a) a queima eficiente que promova redução de insumos madeireiros, da lenha ou outro material combustível; b) a redução de perdas produtivas em função da melhoria do processo de queima; c) a redução de resíduos e poluentes; d) a melhoria do produto final, a partir da melhoria do processo.

Os resultados apontam que a maioria dos entrevistados atribuíram valores de significativa importância para todos os itens, que representam alguns parâmetros ideias de otimização da produção, considerando os ganhos produtivos e ambientais. Esta pesquisa avaliou alguns aspectos ambientais da produção, que envolvem a utilização de insumos madeireiros, bem como o desperdício dos mesmos. Esta avaliação teve foco na queima cerâmica, envolvendo os aspectos ambientais do sistema exterior, abordado pelo MDC (Modelo de Design Concurente), por Hernandis 2003;

4) Aspecto Sócio/Cultural: Os aspectos sócio/culturais que influenciam a falta de modernização das pequenas e médias empresas, a partir do foco da pesquisa, que estuda um dos elos mais críticos desta cadeia produtiva (sistema de queima), este bloco de questões, avaliou dentre os especialistas e empresários do setor, alguns aspectos que influenciam a falta de modernização das pequenas e médias empresas.

Considerando que a maioria das empresas de cerâmica vermelha do Estado do Amazonas se configuram como micro e pequenas empresas à margem dos avanços da modernização tecnológica e ou administrativa, foi verificado dentre os entrevistados algumas razões pelas quais este fato ainda se justifica, sendo julgado por grau de influência elementos que contribuem e/ou explicam este status tecnológico.

Os resultados apontam que a maioria dos entrevistados concordam que a falta de acesso a tecnologias economicamente viáveis influencia muito essa realidade e que o atraso tecnológico é um reflexo das características do setor. Além disso, ao se verificar o resultado, é observado que os entrevistados possuem opiniões divergentes, no que diz respeito a falta de compromisso com as normas vigentes, por parte dos 
empresários e/ou não cobrança devida por parte dos setores públicos responsáveis, caracterizando responsabilidades mútuas, considerando que os agentes, tanto empresários, como poder público possuem uma cota igualitária neste contexto. A última questão deste bloco avalia se a falta de conhecimento, por parte dos empresários, em relação a outras e novas tecnologias também influenciaria para com a continuidade do atraso tecnológico nas pequenas e médias olarias do Estado do Amazonas. Os resultados confirmam a existência de uma influencia significativa neste sentido, permitindo ressaltar que o direcionamento deste estudo para a realidade observada poderá suprir esta demanda de informação e acesso a novas tecnologias, tornando-se justificável o desenvolvimento de um novo sistema que proponha uma alternativa satisfatória.

A partir dos resultados obtidos com a pesquisa realizada por meio de consulta bibliográfica, pesquisa observacional, entrevista a expertises do setor industrial cerâmico e empresários do polo oleiro de Iranduba - Manaus, AM, ficam estabelecidos alguns requisitos de projeto, considerados variáveis de ordem qualitativa e quantitativa que orientam e delimitam o desenvolvimento do novo sistema. Estes requisitos permitem gerar, por meio de parâmetros técnicos, alternativas solucionadoras para o problema pesquisado.

Com base nos aspectos investigados, que refletem os objetivos propostos pelo MDC (Modelo de Design Concorrente, Hernandis 2003), foram organizados em grupos de requisitos, correspondentes as características do problema de pesquisa. Estes grupos de requisitos são apresentados e ordenados pela tabela 01 . 
Tabela 01: Parametrização do Projeto

\begin{tabular}{|l|}
\hline \multicolumn{1}{|c|}{ Requisitos Tecnológicos de projeto } \\
\hline 1) Utilizar sistema de queima invertida; \\
2) Os fatores técnicos operacionais \\
devem ser considerados essenciais no \\
que diz respeito a influência destes sobre \\
a qualidade final dos blocos cerâmicos, \\
otimizando os elementos de apoio que \\
compõem os subsistemas;
\end{tabular}

3) Manter padrão de queima da carga;

4) Gerar calor gradativo com respeito a curva de queima;

5) Modificar a geometria do queimador;

6) A curva de queima deve ser monitorada;

7) O modo do empilhamento da carga na câmara de cocção deve ser planejado, considerando melhor aproveitamento da temperatura;

8) A regulagem e alinhamento dos queimadores devem ser consideradas essenciais;

9) A disposição espacial dos queimadores deve ser considerada em função da distribuição homogênea dos gases quentes durante o processo de queima;

10) Deve haver uma relação funcional e sub sistêmica entre o formato da câmara e os queimadores;

11) Deve ser contemplado o isolamento das paredes dos fornos.

\section{Requisitos Ergonômicos de projeto}

1) Melhorar aspectos macro ergonômicos (conforto ambiental);

2) Melhorar a manipulação da carga antes e depois da queima;

3) Adaptar e ou melhorar os elementos de acionamento dos sistemas;

4) Reduzir a exposição do trabalhador aos agentes nocivos do processo de queima.

\section{Parâmetros tecnológicos de projeto}

- Utilizar processo de queima adiabática;

- Otimizar os aspectos técnicos em função do processo de queima adiabática;

- A curva de queima deve ser monitorada com a utilização de medidores digitais;

- O modo do empilhamento da carga na câmara de cocção deve ser realizado, considerando melhor aproveitamento da temperatura, fazendo uso do método de empilhamento em xadrez (checkerwork) ou em camadas longas (benches), conforme sugerido por Fonseca (1997) apud F. H. Norton (1973), de maneira que permita a circulação dos gases, para se obter uma máxima regularidade da temperatura e do calor. Uma colocação em demasiadamente aberta ou separada permite que os gases passem com certa facilidade, o que não é aconselhável;

- A regulagem e alinhamento dos queimadores devem ser consideradas essenciais, respeitando o método de alimentação das fornalhas, conforme a técnica de queima adiabática e o controle da curva de queima;

- A disposição espacial dos queimadores deve ser considerada em função da distribuição homogênea dos gases quentes durante o processo de queima; Deve haver uma relação funcional e sub sistêmica entre o formato da câmara e os queimadores; Deve ser contemplado o isolamento das paredes dos fornos;

- Deve haver uma otimização espacial e geométrica entre os subsistemas que operam conjuntamente com os queimadores e câmara de cocção.

Parâmetros ergonômicos de projeto

- O novo sistema de queima deve oferecer as condições devidas para que o operador do forno não se exponha ao calor emanado dos queimadores de combustível, não entre em contato com poluentes, como fumaça, agentes químicos e não se exponha a riscos acidentais durante $\mathrm{o}$ processo de abastecimento das fornalhas;

- Deve haver a inserção de um sistema de coleta de cinzas proveniente da queima para facilitar a manutenção e limpeza;

- A adaptação do processo de queima adiabática promove a queima da chama em 


\begin{tabular}{|c|c|}
\hline & $\begin{array}{l}\text { sentido invertido, evitando que o operador } \\
\text { do sistema entre em contato com as } \\
\text { chamas; } \\
\text { O sistema de tiragem (chaminé) promove } \\
\text { tanto o direcionamento do fluxo dos gases } \\
\text { quentes para a área interna da câmara, } \\
\text { quanto o direcionamento da fumaça } \\
\text { ocasionada pela queima; }\end{array}$ \\
\hline Requisitos Ambientais de projeto & Parâmetros Ambientais de projeto \\
\hline $\begin{array}{l}\text { 1) Reduzir fumaça e poluentes } \\
\text { provenientes da queima; } \\
\text { 2) Redução de perdas produtivas; } \\
\text { 3) Redução de insumos madereiros } \\
\text { como fonte energética de queima. }\end{array}$ & $\begin{array}{l}\text { - Deve haver uma redução da queima dos } \\
\text { insumos a partir da otimização da queima } \\
\text { dos mesmos por meio de sistema } \\
\text { adiabático; } \\
\text { - Deve haver uma adaptação entre o processo } \\
\text { de queima tradicional e queima adiabática, } \\
\text { proporcionando eficiência da queima dos } \\
\text { insumos, que consecutivamente reduzirá } \\
\text { perdas produtivas. }\end{array}$ \\
\hline Requisitos Sócio / Culturais de projeto & Parâmetros Sócio / Culturais de projeto \\
\hline $\begin{array}{l}\text { 1) Manter a geometria predominante dos } \\
\text { fornos paulistinha e abóboda; } \\
\text { 2) Manter os materiais constitutivos } \\
\text { comumente utilizados na construção de } \\
\text { fornos tradicionais; } \\
\text { 3) Quebrar paradigmas do retardo } \\
\text { tecnológico das pequenas e médias } \\
\text { olarias; } \\
\text { 4) Motivar e viabilizar o acesso a } \\
\text { tecnologias economicamente viáveis; } \\
\text { 5) Motivar o compromisso com o meio } \\
\text { ambiente. }\end{array}$ & 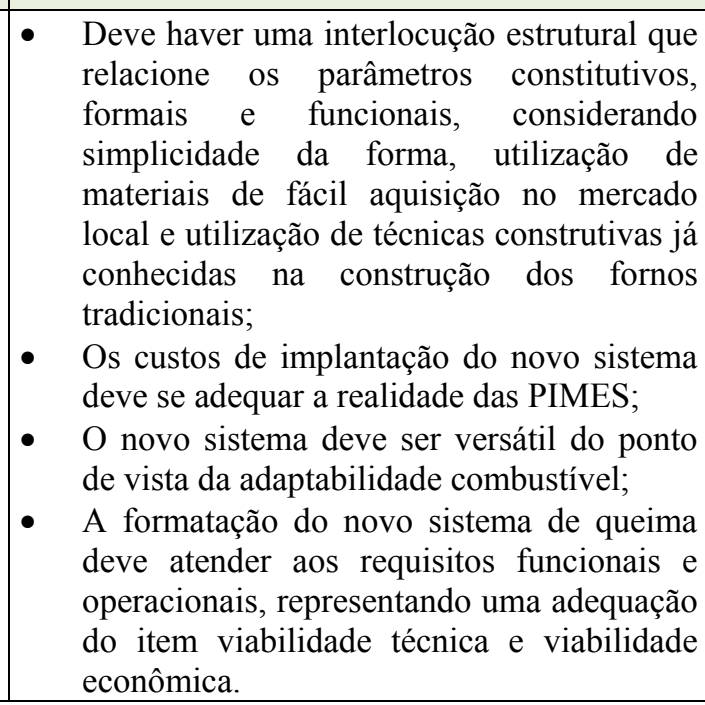 \\
\hline
\end{tabular}

Todos estes requisitos e parâmetros encontram-se distribuídos e interrelacionados no modelo sistêmico aplicado ao desenvolvimento do novo sistema de queima. A aplicação deste método para esta pesquisa se restringiu as análises estrutural, funcional e morfológica, por meio do qual se reconheceu e compreendeu os tipos e números de componentes dos subsistemas envolvidos, bem como princípios de montagem, tipologia de união e estruturas de suporte. A análise funcional permitiu se avaliar as funções técnicas e físicas de cada subsistema, incluindo aspectos ergonômicos (macro análise) do ponto de vista da ergonomia ambiental. Com base em tais análises, as informações daí advindas compuseram a estrutura subsistêmica absorvida pelo modelo de design concorrente (Hernandis 2003).

\subsection{Aplicação do Modelo de Design Concorrente ao Estudo de Caso - Resultados preliminaries.}

Este artigo apresenta a aplicação deste modelo de forma resumida, considerando que a representação completa e aplicada do MDC tornar-se-ia ilegível neste documento, em função de sua estrutura gráfica, portanto, foram resumidas as definições do sistema exterior, objetivos e os subsistemas formal, ergonômico e funcional, bem como suas relações com os aspectos sócio culturais, ambientais e 
tecnológicos, apresentando desta forma os conceitos técnicos do novo sistema de queima para cerâmica estrutural tradicional.

No geral a estrutura do modelo sugerido por Hernandis (2003), tem como objetivo analisar os vários fatores externos ao problema estudado, considerando as interfaces entre o que se está estudando e estes fatores.

A figura 03 apresenta a aplicação deste Modelo de Design Concorrente, como método sistêmico aplicado ao estudo em questão. O Sistema Exterior, prevê especificamente as variáveis de entrada (VE) que determinam o funcionamento do sistema estudado, compondo os objetivos Formais, Funcionais e Ergonômicos do produto. Estes objetivos representam a conversão da problemática detectada por meio da análise do problema, em metas a serem alcançadas. Estas metas possuem VE - Variáveis Essenciais que se relacionam entre si e que formam os subsistemas Formais, Funcionais e Ergonômicos, respectivamente. Entre cada um destes subsistemas, interatuam as diferentes variáveis de ação e de informação que estabelecem o vinculo e a interação, indispensáveis ao funcionamento do modelo. A partir dos subsistemas se estabelecem os volumes de uso, as superfícies de uso e os limites de contorno do produto, elementos delimitadores dos parâmetros que devem possuir o produto conceitual, retroalimentando o modelo e fornecendo assim os meios para se alcançar as metas do projeto.

Os subsistemas funcional, ergonômico e formal foram estudados e desenvolvidos de acordo com as variáveis essenciais e informacionais, advindas de todos os critérios, requisitos e parâmetros definidos como indispensáveis. Considerando que o produto desenvolvido se trata de um sistema aberto e definido como um conjunto de elementos que se relacionam entre si e com o ambiente, havendo, portanto, contextos diferenciados e ao mesmo tempo integrados, sujeitos a sofrer interferencias positivas e negativas, dependendo do modo como este se interfaceia. Neste sentido a estrutura do sistema macro foi dividida em áreas de estudo, sendo elas: a) Área de queima (fornalha, grelha e cinzeiro); b) Área de queima e difusão dos gases (crivos, base subterrânea e chaminé) e; c) Área de empilhamento e queima de carga (câmara, portas e teto). Sobre todas estas áreas e relacionado a cada susbsistema (funcional, ergonômico e formal) todas as áreas foram representadas e desenvolvidas respeitando o volume de uso, superfície de contorno e superfície de uso.

De posse das observações e compilação dos dados acerca do ambiente e influencias que se relacionam com este sistema, foram obtidos, por meio de critérios relativos aos aspectos concernentes ao forno de queima cerâmica, os objetivos formais, funcionais e ergonômicos do novo sistema de queima. A partir da definição de tais objetivos como resultante das variáveis de entrada, foi desenvolvido uma modelagem préliminar de acordo com critérios funcionais, volumétricos e de usabilidade de produto. 


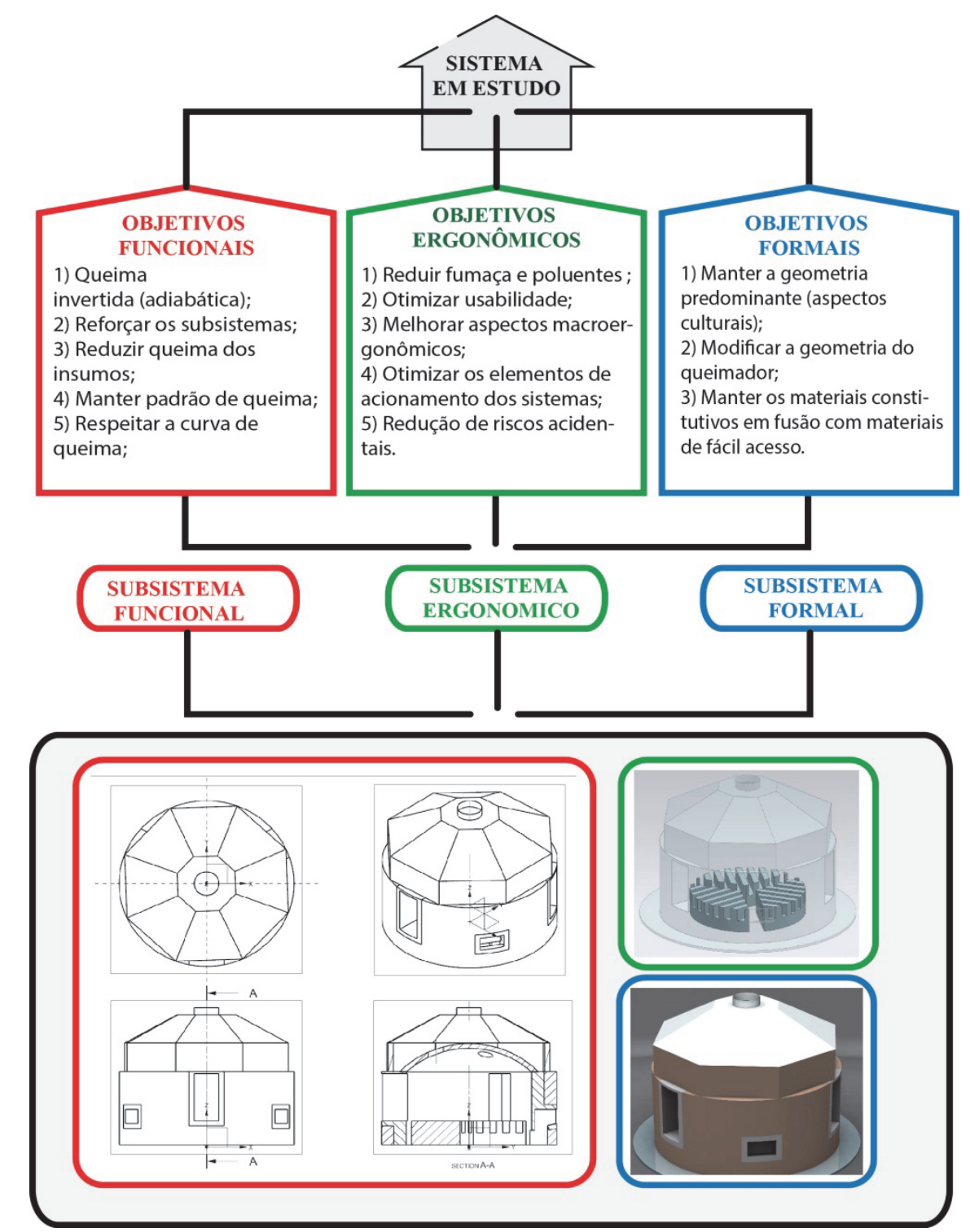

Figura 03: Representação resumida da aplicação do Modelo de Design Concorrente aplicado a fornos tradicionais de cerâmica vermelha no Amazonas - Brasil

\section{Conclusão}

O objetivo desta pesquisa tem como cerne a queima da cerâmica vermelha, cuja motivação se justifica a partir do forte apelo de cunho sustentável que possui, considerando que os resultados pretendidos irão contribuir de maneira considerável para a minimização da queima irregular de lenha, poluição do ar, bem como tornar mais eficiente o processo produtivo e melhorando a qualidade final do produto (tijolo).

A análise sobre a produção de cerâmica vermelha se justifica em função de sua grande projeção de uso em meio as empresas de pequeno e médio porte na região estudada, considerando que todas as empresas utilizam esses modelos de fornos, sejam eles de uso exclusivo ou não. As informações aqui apresentadas se respaldaram tanto em observações realizadas em chão de fábrica, como em entrevistas a expertises do setor e junto aos empresários

Também é importante colocar, que este processo, considerado tradicional, em função de suas características ainda rudimentares, é o segmento produtivo que abastece o setor da indústria civil local, 
em forte crescimento no Estado do Amazonas, contudo, em função das adversidades e limitações existentes no contexto produtivo da cerâmica estrutural tradicional e especificamente amazônico, torna-se cada vez mais necessário e justificável a implementação de mecanismos que possam auxiliar o desenvolvimento de produtos eco eficientes para a indústria, sobre os quais possam atuar os elementos indispensáveis à redução dos impactos ambientais negativos, assim como o uso racional dos recursos naturais.

A utilização do método de Design concorrente para este trabalho, sugerido por Hernandis (2003), possibilitou tanto uma análise pormenorizada do problema em questão, quanto a realização de uma modelagem teórica e prática que se materializará em forma de sistema inovador de queima para cerâmica estrutural, fazendo-se cumprir todos os requisitos inerentes a esta pesquisa.

Os benefícios originados a partir da contribuição do Design Sistêmico para o desenvolvimento de um novo sistema de queima se concretizará por meio dos testes simulados em protótipo, os quais serão divulgados com a continuidade desta pesquisa, contudo os resultados preliminares adiantam a eficácia do método de modelagem sistêmica, garantindo uma estrutura concreta de desenvolvimento projetual.

\section{Agradecimentos}

Sou grata ao CNPQ por me conceder bolsa de estudos de doutorado, número do processo: 207366 / 2014 4. Também agradeço a UFAM - Universidade Federal do Amazonas - Brasil e a UPV - Universidad Politécnica de Valencia - Espanha.

\section{Referências}

ALVES-MAZZOTTI, A. J., \& GEWANDSZNAJDER, F.O (1998) método nas ciências naturais e sociais: pesquisa quantitativa e qualitativa. São Paulo: Pioneira.

BERNI, M. D.. (2010) Oportunidades de eficiência energética na indústria: relatório setorial: setor cerâmico / Mauro donizeti Berni, Sérgio Valdir Bajay, filipe d. gorla. - Brasília: cni, 2010. 75 p. ISBN 978-85-7957-008-7.

BONSIEPE, GUI E OUTROS. Metodologia Experimental: Desenho Industrial. Brasília: CNPq/Coordenação Editorial, 1986.

BORGES, T. P. F., Fogão a Lenha de Combustão Limpa. MSc. Thesis. Universidade Estadual de Campinas. 1994.

BRIEDE, J., \& HERNANDIS, B. (2011). New Methods in Design Education: The Systemic Methodology and the Use of Sketch in the Conceptual Design Stage. . Us-China Education Review , 8 (11), 118-128.

CARVAlHO, J. L. F.; VERGARA, S. C. A fenomenologia e a pesquisa dos espaços de serviços. Revista de Administração de Empresas - RAE, v. 42, n. 3, jul./set. 2002.

FURG, Portal dos alunos de engenharia civil. Materiais - Desperdício. Disponível em $<$ www.projetoeconstrucao.hpg.ig.com.br> .

HERNANDIS, B. (2012). Diseño Concurrente. En R. Martins, \& J. van der Linden, PELOS CAMINHOS DO DESIGN: Metodologia de Projeto (págs. 327-391). Londrina, Brasil: EDUEL.

HERNANDIS, B. (2003). Tesis Doctoral:Desarrollo de una metodología sistémica para el diseño de productos industriales. . Valencia, España: Universidad Politécnica de Valencia.

HERNANDIS, B. ;BRIEDE, J. (2009).An Educational Application for a Product design and Engineering systems using integrated conceptual models.(pp.432-442)Arica. Ingeniare. Revista Chilena de Ingeniería.

IIDA, Itiro. Ergonomia: projeto e produção. São Paulo. 2a edição. Edgar Blucher LTDA 2005.465p.

KHAN, A. M. HASAN, SHUTTE, E., “et al.” (1989): Application of Downdraft Combustion to Woodburning Devices. WSG Publicação Interna vol., 6 páginas.

MOTA, S. C; SOUZA, R. C. R; MARTINS, G. (2006) - Technical and ergonomic improvements in the furnace design of a manioc flour house. Artigo dos anais do 16th World Congress on Ergonomics - IEA. Associação International de Ergonomia. HOLANDA. Edited by R.N. Pikaar Eur.Erg., E.A.P. Koningsveld Eur.Erg. and P.J.M. Settels Eur.Erg., ISSN 0003-6870, Elsevier Ltd. 
O design sistémico como método de inovação aplicado a fornos tradicionais de cerámica vermelha no Amazonas.

MOTA, S. C. ; SOUZA, R.C.R. . Inovação Tecnológica e Melhorias no Design do Forno da Casa de Farinha.. In: XXVII ENEGEP 2007, Foz do Iguaçu.

MOTA, S. C. ; HERNANDIS, B.; MAZARELO, K. P.; BATALHA V. \& VERGARA L. (2015) Ecoeficiency and Enviroment Ergonomics to the production of ceramic bricks in the Brazilian Amazon - 6th International Conference on Applied Human Factors and Ergonomics (AHFE 2015) and the Affiliated Conferences, AHFE 2015.

MINAYO, M. C. S. Pesquisa social: teoria, método e criatividade. Rio de Janeiro: Vozes, 2001.

NEAPL - Núcleo Estadual de Arranjos Produtivos Locais - Plano de Desenvolvimento Preliminar APL de Base Mineral - Cerâmico Oleiro - Cidade Polo Iranduba - 2009

PACHECO, K., HERNANDIS, B., \& PAIXÃO-BARRADAS, S. (2012). La importancia del diseño sistémico para la competitividad de la fibra natural Amazónica de tucumã-i (Astrocaryum acaule) en el desarrollo semi-industrial de productos: Un estudio de caso para la categoría del vestuario. En U. R. Llull (Ed.), $2^{\circ}$ Congreso Internacional de Diseño e Innovación. Sabadell: Escuela Superior de Diseño ESDi.

PAIXÃO-BARRADAS, S., PACHECO, K., \& HERNANDIS, B. (2011). Design mediante o uso de materiais naturais: análise de atributos essenciais ao desenvolvimento de novos produtos. Lisboa: VI Congresso Internacional de Pesquisa de Design, 10-12 Outubro.

PAIXÃO-BARRADAS, S., PACHECO, K., \& HERNANDIS, B. (2012). La piedra natural como un material de diseño para el desarrollo de equipamiento urbano: reporte de un caso. ICONOFACTO , 8 (11), 77-95 .

RELATÓRIO ARRANJOS Produtivos Locais - APLs - GRUPO DE PESQUISAS EM MATERIAIS DE ENGENHARIA/UFAM - EDITAL MCT/CT-Mineral/CNPq No 44/201

RIVERA, J.; HERNANDIS, B.; MOTA, S. \& MIRANDA, (2015). O. Immaterial elements as drivers of sustainability in products and services. The 22nd CIRP conference on Life Cycle Engineering. 2212-8271 (C) Published by Elsevier B.V. Conference "22nd CIRP conference on Life Cycle Engineering.

SECRETARIA DE PLANEJAMENTO E DESENVOLVIMENTO ECONÔMICO DO ESTADO DO AMAZONAS. Legislação de Incentivos Fiscais do Amazonas. Lei nº 2.826/2003 - Amazonas: SEPLAN, 2009.

SCHUMAN, H.,\& KALTON,G.(1985).Surveymethods. Em G.Lindzey\&E.Aronson(eds.), Handbook of social psychology, 3rd ed. Vol. 11 - 1985. NewYork: RandomHouse.

SILVA, M. M. PEREIRA DA. Avaliação de perdas de blocos cerâmicos em Pernambuco: da Indústria ao Canteiro de obras. Dissertação Mestrado - Universidade Católica de Pernambuco. Curso de Mestrado Engenharia Civil 2007. Fonte: $<$ http://www.unicap.br/tede//tde_busca/arquivo.php?codArquivo=340>, [acessado em 25/02/14]

SWANN, C. (2002). Action Research and the Practice of Design. . Design Issues. , 18, 49- 61. 